\title{
CSF neurofilament light chain testing as an aid to determine treatment strategies in MS
}

Saúl Reyes, MD, * Ide Smets, PhD, * David Holden, PhD, Karina Carrillo-Loza, MD, Tatiana Christmas, MD, Lucia Bianchi, PhD, Francesca Ammoscato, PhD, Benjamin Turner, MD, Monica Marta, PhD,

Klaus Schmierer, PhD, Gavin Giovannoni, PhD, and Sharmilee Gnanapavan, PhD

Neurol Neuroimmunol Neuroinflamm 2020;7:e880. doi:10.1212/NXI.0000000000000880

\section{Abstract}

\section{Objective}

To evaluate the use of CSF neurofilament light chain (NfL) measurements in clinical practice as well as their effect on treatment strategies and outcomes in patients with MS.

\section{Methods}

This was an observational cohort study of patients with MS who had a CSF NfL measurement between December 2015 and July 2018 as part of their routine clinical care. Treatment strategies were classified as "No Treatment/No Escalation" (no treatment or no escalation of treatment) or "Treatment/Escalation" (first-line injectable/oral disease-modifying therapies (DMTs), highly active DMTs, or treatment escalation). Change in Expanded Disability Status Scale (EDSS) scores was evaluated after 1-year follow-up.

\section{Results}

Of 203 patients with MS, 117 (58\%) had relapsing-remitting MS. Disease activity was most frequently indicated by elevated CSF NfL $(n=85)$, followed by clinical $(n=81)$ and MRI activity $(\mathrm{n}=65)$. CSF NfL measurements were independently associated with clinical $(p=$ $0.02)$ and MRI activity $(p<0.001)$. Of those with elevated CSF NfL as the only evidence of disease activity $(\mathrm{n}=22), 77 \%$ had progressive MS (PMS). In patients with PMS, $17(20 \%)$ had elevated CSF NfL as the sole indicator of disease activity. Elevated CSF NfL resulted more frequently in Treatment/Escalation than normal CSF NfL $(p<0.001)$. Median EDSS change at follow-up was similar between patients receiving No Treatment/No Escalation and Treatment/Escalation decisions $(p=0.81)$.

\section{Conclusions}

CSF NfL measurements informed treatment strategies, alongside clinical and MRI measures. CSF NfL levels were the only indicator of disease activity in a subset of patients, which was more pronounced in patients with PMS. Elevated CSF NfL was associated with more Treatment/ Escalation strategies, which had an impact on EDSS outcomes at 1 year.
Correspondence

Dr. Gnanapavan

s.gnanapavan@qmul.ac.uk 


\section{Glossary}

DMT = disease-modifying therapy; EDSS = Expanded Disability Status Scale; Gd = gadolinium; $\mathbf{I Q R}=$ interquartile range; NEDA = no evident disease activity; $\mathbf{N f L}$ = neurofilament light chain; PMS = progressive MS; RRMS = relapsing-remitting MS .

The availability of new and more effective disease-modifying therapies (DMTs) has increased the complexity of MS management. ${ }^{1}$ Moreover, the clinical and pathologic heterogeneity throughout the disease course of MS poses major challenges for treatment decisions. ${ }^{2}$ Treatment strategies in MS are largely based on clinical activity (including relapses) and MRI findings (new or enlarging T2 lesions and/or gadolinium [Gd]-enhancing lesions). ${ }^{3,4}$ However, it is not possible to capture the full extent of disease activity with these measures, and the correlation between MRI measures and clinical disability remains limited. ${ }^{5-7}$ As a result, treatment strategies based solely on these disease activity markers may fail to deliver the best possible long-term outcomes. ${ }^{5}$

Personalization of MS management is a key goal for all MS practices. There is, thus, an unmet need for additional biomarkers that enable neurologists to further stratify treatment strategies and improve outcomes for individual patients. As elevated CSF neurofilament light chain (NfL) measurements can indicate ongoing inflammation and neuroaxonal degeneration in MS, ${ }^{8,9}$ measurement of CSF NfL may represent an additional tool to assist in the treatment decision-making process. CSF NfL measurements have been shown to correlate with clinical and radiologic disease activity and predict disability progression. ${ }^{9-11}$ Moreover, reduction of CSF NfL measurements also indicates response to treatment. ${ }^{12-14}$ However, the utility of CSF NfL measurement in day-to-day clinical practice remains largely unexplored. Specifically, we do not know what form this will take over and above that of clinical and MRI activity and whether using CSF NfL in the treatment decisionmaking process has any impact on outcomes.

At our center, CSF NfL testing has been provided to assist treatment decision making since December 2015. In this cohort study, we aimed to (1) characterize the distribution of disease activity as measured by CSF NfL, clinical activity, and MRI activity, (2) evaluate the influence of CSF NfL measurements on treatment strategies, (3) evaluate the impact of CSF NfL-based treatment strategies on disability outcomes, and (4) evaluate the impact of the CSF NfL on our clinical practice following its introduction.

\section{Methods}

\section{Study design and participants}

This was an observational cohort study based at Barts Health NHS Trust, London, United Kingdom. Patients with either relapsing-remitting MS (RRMS) or progressive MS (PMS) who underwent CSF NfL measurements between December 2015 and July 2018 were identified from our institutional database. Inclusion criteria were age $\geq 18$ years, having a treatment decision that took into account CSF NfL measurements, clinical and MRI assessments, and having an Expanded Disability Status Scale (EDSS) score obtained at least 1 year after the treatment decision.

\section{Standard protocol approvals, registrations, and patient consents}

This study was approved by the London City and East Research Ethics Committee (REC ref: 20/LO/0023). Informed and signed consent for lumbar puncture was obtained from all patients. This study was conducted according to the Strengthening the Reporting of Observational Studies in Epidemiology (STROBE) reporting guideline. ${ }^{15}$

\section{Demographics and MS disease characteristics}

Demographics and disease characteristics were extracted from the participants' electronic medical record as follows: age, sex, type of MS (RRMS or PMS), current DMT status, disease duration, clinical and radiologic disease activity at baseline, baseline EDSS score, follow-up EDSS score, and EDSS change. Disease duration was defined as the number of years from the first episode of focal neurologic dysfunction suggestive of demyelination. The baseline EDSS score was assessed within 1 year before treatment decision, and the follow-up EDSS score was assessed at least 1 year after the treatment decision. EDSS change was calculated by subtracting the follow-up EDSS score from the baseline EDSS score. Clinical activity was defined as relapses (the occurrence of new or recurrent neurologic symptoms) and/or sustained disability progression (i.e., sustained increase from the baseline EDSS score of $\geq 1$.0. over a $\geq 3$-month period). Radiologic activity was defined as (1) at least 1 clearly identifiable new lesion and/or increase in size of a preexisting lesion on T2weighted MRI and/or (2) at least $1 \mathrm{Gd}$-enhancing lesion on contrast-enhanced T1-weighted MRI.

\section{CSF NfL measurements}

CSF samples were obtained by lumbar puncture using an atraumatic procedure ${ }^{16}$ and collected in polypropylene tubes. CSF samples were centrifuged at $400 \mathrm{rpm}$ for 10 minutes and aliquoted and stored at $-80^{\circ} \mathrm{C}$ until use. CSF NfL measurements were measured in the neuroimmunology laboratory at the Blizard Institute, Queen Mary University of London, London, United Kingdom, using the commercially available and validated solid-phase sandwich ELISA from UmanDiagnostics (Umeå, Sweden). ${ }^{17}$ The test used 2 highly specific noncompeting monoclonal antibodies: an NfL-capturing antibody coated to the solid phase of a strip plate and a tracer antibody conjugated to horseradish peroxidase for the detection of captured NfL protein. ${ }^{17}$ 
CSF NfL measurements $(\mathrm{pg} / \mathrm{mL})$ were calculated using a standard curve according to the manufacturer's instructions. ${ }^{18}$ The detection limit of the ELISA was $33 \mathrm{pg} / \mathrm{mL}$. Intra- and interassay coefficients of variation were below $10 \%$. All NfL analyses were performed in duplicate. CSF NfL measurements were categorized as normal or elevated according to age-related reference values defined by the manufacturer. ${ }^{18}$ These reference ranges have been established in 50 volunteers that had no apparent neurologic disease based on interviews by a research nurse and MRI. The healthy subjects were divided into 3 age groups, and the reference levels were defined as median NfL level +2 SDs. In patients aged $<30$ years $(\mathrm{n}=$ 17), the cutoff was $290 \mathrm{pg} / \mathrm{mL}$ (median $186.4 \mathrm{pg} / \mathrm{mL}, 2 \mathrm{SD}$ $100)$, in patients aged between 30 and 39 years $(n=15) 380$ $\mathrm{pg} / \mathrm{mL}$ (median $288.4 \mathrm{pg} / \mathrm{mL}, 2$ SD 94.5), and in patients aged between 40 and 59 years $(\mathrm{n}=18) 830 \mathrm{pg} / \mathrm{mL}$ (median $490.6 \mathrm{pg} / \mathrm{mL}, 2$ SD 340). ${ }^{18}$

\section{Treatment strategies}

The Barts MS center has implemented a local strategy of treating to a target of no evident disease activity (NEDA). Although we used CSF NfL measurements for NEDA assessment in MS, there was no specific algorithm for DMT selection based on NfL testing at our center. The decision on which DMT to prescribe was at the discretion of each MS consultant. Treatment strategies were classified as follows based on NHS England treatment algorithm and local prescribing policies ${ }^{19}$ : (1) "no treatment" when patients were not started on any DMT, (2) "no escalation of treatment" when previously treated patients continued on the same DMT, (3) "first-line injectable and oral DMTs" when treatment naive patients received beta-interferons, glatiramer acetate, teriflunomide, or dimethyl fumarate, (4) "highly active DMTs" when naive patients received high efficacy oral (fingolimod), subcutaneous cladribine or infusion therapies (natalizumab, ocrelizumab, or alemtuzumab), and (5) "treatment escalation" when previously treated patients according to (2) and (4) were escalated to more effective DMTs. We defined treatment strategies (1) and (2) as "No Treatment/No Escalation" and (3), (4) and (5) as "Treatment/Escalation."

\section{Statistical analysis}

Categorical variables were described as frequency and percentages and continuous and ordinal variables by median and interquartile range (IQR). CSF NfL levels were tested for normality using the Shapiro-Wilk test. As they were not normally distributed, pairwise comparisons were conducted with the Kruskal-Wallis test. Frequencies of grouped treatment strategies per year were compared using the $\chi^{2}$ test. Two-way analysis of variance was performed to model CSF NfL measurements as a function of MRI and clinical activity taking into account covariates that were significantly associated with CSF NfL measurements. We checked for significant interactions between MRI and clinical activity and performed a sensitivity analysis in which extreme NfL values were replaced by the mean \pm 3 SDs. A nominal significance threshold $(p=0.05)$ was applied, and all tests were 2 sided. All analyses were performed using the statistical package $\mathrm{R}$ v3.6.1.

\section{Data availability}

All data included in these analyses will be shared as anonymized data via request from any qualified investigator.

\section{Results}

\section{Patient characteristics}

A total of 203 patients with MS were included in the study, with a median age of 44 years (IQR 33-52 years), 123 (61\%) were female and 117 (58\%) had RRMS. The median EDSS score was 3 (IQR 1.5-6), and the median disease duration was 6 years (IQR 2-13 years). At baseline, 169 (83\%) patients were not treated with any DMT (table 1).

\section{The distribution of disease activity as measured by CSF NfL, clinical activity, and MRI activity}

There was no evidence of clinical or MRI activity or elevated CSF NfL in 64 patients, whereas in 139 patients, at least 1 category signaled active disease (figure 1). Among those with disease activity, all 3 parameters were present in 21 patients $(15 \%)$, while the frequency of disease activity was in the order of elevated CSF NfL $(n=85)>$ clinical activity $(n=81)>$ MRI activity $(n=65)$. In those without clinical activity, disease activity was still demonstrated in 39 patients through elevated CSF NfL and in 36 patients having an active MRI, with 17 patients displaying both (figure 1). CSF NfL was associated with MRI activity $(p<0.01)$ and with Gdenhancing lesions $(p<0.001)$ (figure 2 , A and B). CSF NfL was also associated with clinical activity $(p<0.001)$ and with relapses $(p<0.01)$ (figure $2, \mathrm{C}$ and $\mathrm{D})$.

When integrating both MRI and clinical variables in the same model, we demonstrated that NfL measurements were independently associated with clinical $(b=391.49, p=0.02)$ and MRI activity ( $b=766.31, p<0.001$ ) (figure $2 \mathrm{E}$ ). No statistically significant interaction between MRI activity and clinical activity was observed in the model $(p=0.06)$. These results survived a sensitivity analysis (clinical activity: $\mathrm{b}=$ 252.96, $p=0.03$; MRI activity: $\mathrm{b}=566.94, p<0.001)$. CSF $\mathrm{NfL}$ measurements were significantly higher in men than in women $(p<0.001)$ and were also associated with current treatment status $(p<0.01)$, which were both controlled for in the regression analysis.

\section{The influence of CSF NfL measurements on treatment strategies}

In 22 patients with MS (11\%), the only evidence of disease activity used in the treatment decision-making process was their elevated CSF NfL measurement ("CSF NfL only" patients). The majority (77\%) of these had PMS compared with $42 \%$ in the "MRI activity only" and $48 \%$ in the "clinical activity only" subgroup (table 1). CSF NfL only patients had a median disease duration of 8 years (IQR 4-10.8 years) and a median 
Table 1 Baseline characteristics of the study cohort by disease activity status ${ }^{a}$

\begin{tabular}{|c|c|c|c|c|c|c|c|c|c|}
\hline Characteristic $^{\mathbf{b}}$ & $\begin{array}{l}\text { Patients } \\
\text { with MS } \\
(N=203)\end{array}$ & $\begin{array}{l}\text { "NfL only" } \\
\text { patients with } \\
\text { MS }(n=22)\end{array}$ & $\begin{array}{l}\text { "MRI activity } \\
\text { only" patients } \\
\text { with MS }(n=19)\end{array}$ & $\begin{array}{l}\text { "Clinical activity } \\
\text { only" patients } \\
\text { with MS ( } n=27)\end{array}$ & $\begin{array}{l}\text { “NfL and clinical } \\
\text { activity" patients } \\
\text { with MS ( }(n=25)\end{array}$ & $\begin{array}{l}\text { "NfL and MRI } \\
\text { activity" patients } \\
\text { with MS ( }(n=17)\end{array}$ & $\begin{array}{l}\text { "Clinical and MRI } \\
\text { activity" patients } \\
\text { with MS }(n=8)\end{array}$ & $\begin{array}{l}\text { "NfL, MRI activity, and } \\
\text { clinical activity" } \\
\text { patients with MS }(n=21)\end{array}$ & $\begin{array}{l}\text { "No activity" } \\
\text { patients with } \\
\text { MS }(n=64)\end{array}$ \\
\hline \multicolumn{10}{|l|}{ Sex, no. (\%) } \\
\hline Female & $123(60.6)$ & $6(27.3)$ & $13(68.4)$ & $19(70.4)$ & $16(64)$ & $10(58.8)$ & $6(75)$ & $11(52.4)$ & $42(65.6)$ \\
\hline Male & 80 (39.4) & $16(72.7)$ & $6(31.6)$ & 8 (29.6) & $9(36)$ & $7(41.2)$ & $2(25)$ & $10(47.6)$ & $22(34.4)$ \\
\hline Age, median (IQR) & $44(33-52)$ & $46(38.3-57)$ & $46(39-53)$ & $49(44.5-59)$ & $33(29.5-45.5)$ & 35 (27-49.5) & 38.5 (33.5-44.5) & $33(28-41)$ & $47(40-54)$ \\
\hline \multicolumn{10}{|l|}{ Type of MS, no. (\%) } \\
\hline RRMS & $117(57.6)$ & $5(22.7)$ & $11(57.9)$ & 14 (51.9) & $19(76)$ & $12(70.6)$ & $7(87.5)$ & $17(81)$ & $32(50)$ \\
\hline PMS & $86(42.4)$ & $17(77.3)$ & $8(42.1)$ & $13(48.1)$ & $6(24)$ & $5(29.4)$ & $1(12.5)$ & $4(19)$ & $32(50)$ \\
\hline $\begin{array}{l}\text { Disease duration, } \\
\text { median (IQR) }\end{array}$ & $6(2-13)$ & $8(4-10.8)$ & $8(2.25-11)$ & $9(2-16.5)$ & $4(1-7)$ & $5(1-14)$ & $3.5(2.5-4.5)$ & $2(1-10)$ & $9(4-18)$ \\
\hline $\begin{array}{l}\text { Baseline EDSS score, } \\
\text { median (IQR) }\end{array}$ & $3(1.5-6)$ & $6(4-6.5)$ & $3(1.5-6)$ & $3(2-5.3)$ & $3(1.5-5.3)$ & $2(1-4.3)$ & $1.3(1-1.5)$ & $2(1-3.5)$ & $4(2-6.5)$ \\
\hline \multicolumn{10}{|l|}{ DMTs, no. (\%) } \\
\hline None & $169(83.3)$ & $21(95.5)$ & $17(89.4)$ & $23(85.2)$ & $24(96)$ & $15(88.2)$ & $7(87.5)$ & $17(81)$ & $45(70.3)$ \\
\hline Alemtuzumab & $1(0.5)$ & - & - & - & - & - & - & - & $1(1.6)$ \\
\hline Beta-interferon & $1(0.5)$ & - & - & - & - & - & - & - & $1(1.6)$ \\
\hline $\begin{array}{l}\text { Cladribine } \\
\text { (subcutaneous) }\end{array}$ & $6(3.0)$ & $1(4.5)$ & $1(5.3)$ & $2(7.4)$ & - & - & - & $1(4.8)$ & $1(1.6)$ \\
\hline Dimethyl fumarate & $8(4.0)$ & - & - & $1(3.7)$ & - & $1(5.9)$ & $1(12.5)$ & $2(9.5)$ & $3(4.7)$ \\
\hline Fingolimod & $11(5.4)$ & - & $1(5.3)$ & $1(3.7)$ & $1(4)$ & - & - & $1(4.8)$ & $7(10.9)$ \\
\hline Glatiramer acetate & $1(0.5)$ & - & - & - & - & - & - & - & $1(1.6)$ \\
\hline Natalizumab & $6(3.0)$ & - & - & - & - & $1(5.9)$ & - & - & $5(7.8)$ \\
\hline
\end{tabular}

Abbreviations: DMT = disease-modifying therapy; EDSS = Expanded Disability Status Scale; IQR = interquartile range; NfL = neurofilament light chain; PMS = progressive MS; RRMS = relapsing-remitting MS.

a NfL only, MRI only, and clinical only correspond to patients with MS who had only elevated CSF NfL, clinical activity, or MRI activity, respectively. Combined disease activity groups are also provided.

b Each characteristic's percentage represents their respective weight among the total patients in each disease activity group. 
Figure 1 Venn diagram illustrating the distribution of disease activity among patients with MS in our cohort $(n=203)$

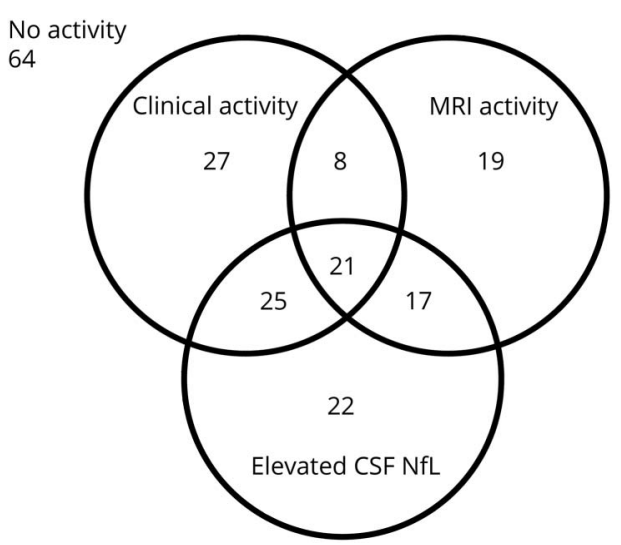

$\mathrm{NfL}=$ neurofilament light chain

baseline EDSS score of 6 (IQR 4-6.5). Distribution of demographic characteristics by disease activity status is summarized in table 1 .

In patients with PMS, 62 of 86 (72\%) had treatment strategies including elevated CSF NfL measurements in the process, and in 17 (20\%) an elevated CSF NfL measurement was the only evidence of disease activity used in the treatment decisionmaking process. In patients with RRMS, 75 of 117 (64\%) had treatment strategies integrating elevated CSF NfL measurements with other measures, and in 5 (4\%), elevated CSF NfL measurements were the only disease activity criterion used in the treatment decision-making process.

Treatment strategies consisted of No Treatment/No Escalation decisions in 62 patients (30.5\%) and Treatment/ Escalation decisions in 141 patients (69.5\%) (table 2). Higher median CSF NfL measurements were observed for patients ultimately receiving a Treatment/Escalation decision $(612$ $\mathrm{pg} / \mathrm{mL}$ ) compared with No Treatment/No Escalation patients $(264.5 \mathrm{pg} / \mathrm{mL})(p<0.001)$ (table 2, figure $3 \mathrm{~A})$. In the No Treatment/No Escalation group, there was little difference between median CSF NfL measurements of patients for whom we decided not to treat $(264.5 \mathrm{pg} / \mathrm{mL})$ compared with those whose treatment was not escalated $(269 \mathrm{pg} / \mathrm{mL})$. In the Treatment/Escalation group, there was a stepwise increase in median CSF NfL values from patients put on first-line injectable and oral DMTs $(369 \mathrm{pg} / \mathrm{mL})$, to those started on highly active DMTs $(411 \mathrm{pg} / \mathrm{mL})$, and those whose treatment was escalated $(696 \mathrm{pg} / \mathrm{mL})$.

\section{The impact of CSF NfL-based treatment strategies on disability outcomes}

Of the 95 patients in the No Treatment/No escalation group, the median baseline EDSS score was 2.5 (IQR 1.5-6), and the median follow-up EDSS score was 2.5 (IQR 1.5-6). Of the
108 patients in the Treatment/Escalation group, the median baseline EDSS score was 4 (IQR 1.75-6), and the median follow-up EDSS score was 4.75 (IQR 2-6). The median EDSS change was 0 (IQR 0-0.5) in both the No Treatment/ No Escalation and the Treatment/Escalation group. The change in the EDSS was not found to be different at follow-up between the 2 treatment groups $(p=0.81)$ (figure 3B).

\section{CSF NfL test experience (December 2015-July 2018)}

The learning effect and adoption of the CSF NfL test was evaluated over the period of December 2015 through to July 2018 based on clinical documentation. The proportion of Treatment/Escalation vs No Treatment/No Escalation strategies did not differ from year to year in patients with elevated CSF NfL measurements ( $p=0.99$ ) (figure S1A, links. lww.com/NXI/A307); while in patients with normal CSF NfL measurements the proportion of No Treatment/No Escalation strategies significantly increased toward 2018 ( $p<$ 0.02) (figure S1B).

\section{Discussion}

In the present study, we evaluated the use of CSF NfL measurements to assist treatment strategies for patients with MS in clinical practice. Although CSF NfL has gained traction in research as a tool to identify disease activity in MS, it is not known whether the same applies for clinical practice, particularly that of personalized care. We explored the utility of the CSF NfL test in real-life practice.

In our cohort, we found that CSF NfL measurements were elevated in $42 \%$ of samples tested. Although CSF NfL closely aligned with clinical disease activity and MRI activity, all 3 parameters were present together in only a small proportion of patients (15\%). CSF NfL measurements have been shown to reflect both inflammatory and neurodegenerative components of MS, ${ }^{8,9,12,20,21}$ which is supported by our finding that CSF NfL was not only associated with relapses and Gdenhancing lesions on MRI but also with our composites of clinical and radiologic disease activity. However, modeling CSF NfL with the other 2 disease activity parameters showed that these associations were largely independent of each other. Recently, both CSF and serum NfL measurements have been shown to correlate not only with current but also with previous clinical and MRI activity in RRMS. ${ }^{22,23}$ Although assessments of disease activity (i.e., CSF NfL testing and clinical and radiologic assessments) were deemed to take place within a similar time frame, no predefined time intervals were set for this real-word study. This may explain the lack of association between CSF NfL measurements and some clinical and MRI measures evaluated in our study. The reasons for the association between sex and CSF NfL measurements found in our study remain uncertain. However, our findings are in line with the results of other studies showing that CSF $\mathrm{NfL}$ levels are significantly higher in men compared with 


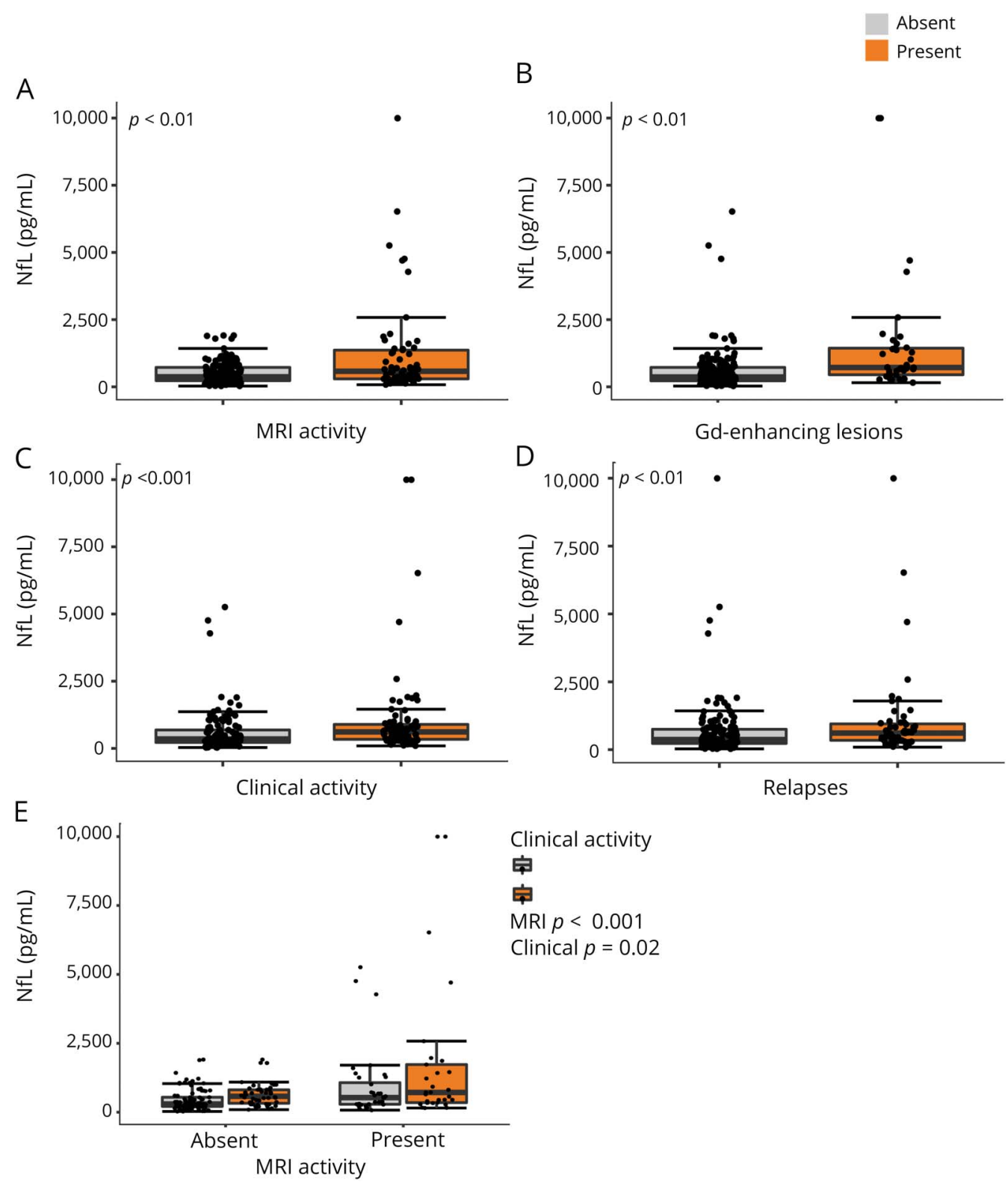

Box plots demonstrating the relationship between CSF NfL $(n=203)$ and (A) MRI activity (new/enlarging lesions and/or Gd-enhancing lesions), (B) Gdenhancing lesions, (C) clinical activity (relapses and/or progression), and (D) relapses. (E) Regression modeling NfL measurements as a function of clinical activity (relapses and/or progression) and MRI activity (new/enlarging lesions and/or Gd-enhancing lesions). Box-whisker plots represent median, quartiles, and $1.5 \times$ interquartile range. $\mathrm{Gd}=$ gadolinium; $\mathrm{NfL}=$ neurofilament light chain.

women in healthy individuals and several neurodegenerative diseases. $^{24}$

Most of the patients demonstrating an elevated CSF NfL measurement as the only evidence of disease activity had a progressive disease course. This observation was less apparent when looking at the clinical activity only or MRI activity only subgroups. Similarly, an elevated CSF NfL measurement was the only evidence of disease activity used in the treatment decision-making process in one-fifth of the patients with PMS within this cohort. This suggests that there is a subgroup of patients with MS with disease activity that may be missed by relying on clinical activity or MRI disease activity markers alone. $^{7,25}$ Although a number of publications report on elevated CSF NfL during relapse in RRMS, subclinical inflammatory disease activity in PMS is often overlooked. ${ }^{7}$ Elevated CSF NfL in isolation may therefore still be acted on and has the potential to be much more than an aid for prognostication or treatment response.

Although CSF NfL measurements were only 1 of the 3 pillars in assessing disease activity during the treatment decision- 
Table 2 Treatment strategies according to CSF NfL measurements

\begin{tabular}{|c|c|c|c|c|c|}
\hline \multirow[b]{2}{*}{ Treatment strategy } & \multicolumn{2}{|c|}{$\begin{array}{l}\text { Elevated CSF NfL } \\
\text { measurements }(n=85)\end{array}$} & \multicolumn{2}{|c|}{$\begin{array}{l}\text { Normal CSF NfL } \\
\text { measurements }(n=118)\end{array}$} & \multirow{2}{*}{$\begin{array}{l}\text { All patients }(\mathrm{N}=203) \\
\text { Median } \mathrm{CSF} \\
\mathrm{NfL}(\mathrm{pg} / \mathrm{mL})\end{array}$} \\
\hline & No. (\%) & $\begin{array}{l}\text { Median CSF } \\
\mathrm{NfL}(\mathrm{pg} / \mathrm{mL})\end{array}$ & No. (\%) & $\begin{array}{l}\text { Median CSF } \\
\mathrm{NfL}(\mathrm{pg} / \mathrm{mL})\end{array}$ & \\
\hline No treatment/escalation & $4(4.7)$ & 701 & $58(49.2)$ & 239 & 264.5 \\
\hline No treatment & $1(1.2)$ & 861 & 35 (29.7) & 264 & 264.5 \\
\hline No escalation of treatment & $3(3.5)$ & 453 & $23(19.4)$ & 246 & 269 \\
\hline Treatment/escalation, no. (\%) & $81(95.3)$ & 971 & $60(50.8)$ & 297 & 612 \\
\hline First-line injectable and oral DMTs & $15(17.6)$ & 808 & $18(15.3)$ & 169 & 369 \\
\hline Highly active DMTs & $61(71.8)$ & 996 & 35 (29.7) & 295 & 411 \\
\hline Treatment escalation & $5(5.9)$ & 682 & $7(5.9)$ & 335 & 696 \\
\hline
\end{tabular}

Abbreviations: DMT = disease-modifying therapy; $\mathrm{NfL}$ = neurofilament light chain.

making process, patients with elevated CSF NfL were more likely to be directed toward Treatment/Escalation strategies in our study. The EDSS outcomes at follow-up between the No Treatment/No Escalation and Treatment/Escalation strategies did not differ significantly in this study, suggesting counterpoise. This is in line with current evidence that more aggressive treatment strategies lead to better clinical outcomes and higher rates of NEDA. ${ }^{5,26}$ Moreover, early treatment in MS has been found to reduce the risk of converting from RRMS to PMS. ${ }^{27-29}$ As CSF measurements of NfL predict future disability progression in patients with $\mathrm{MS},{ }^{11}$ adding CSF NfL measurements in the workup of patients with MS, starting with the diagnostic lumbar puncture, may help refine treatment strategies (highly active vs first-line therapies).

A key hurdle for any new biomarker or treatment is the adoption in clinical practice, which is dependent on evidence combined with the willingness and feasibility to introduce the novelty. ${ }^{30}$ In our center, we did not detect a meaningful change in treatment strategies in those with elevated CSF NfL over time, whereas more No Treatment/ No Escalation decisions were documented in those with normal CSF NfL measurements toward the end of the study period. Arguably, although an important reason for the adoption of CSF NfL has been to identify patients with

Figure 3 The influence of CSF NfL on treatment strategies and disability outcomes

A

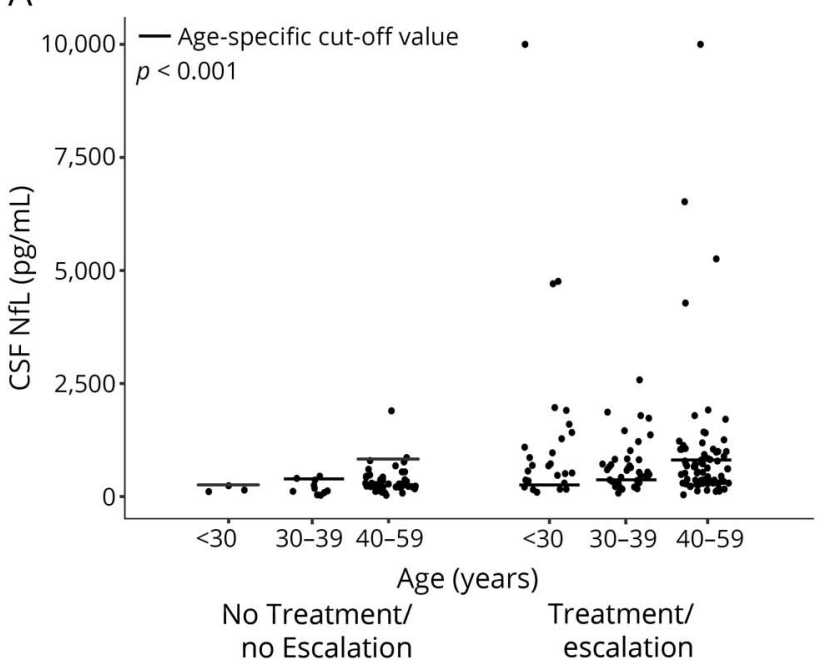

B

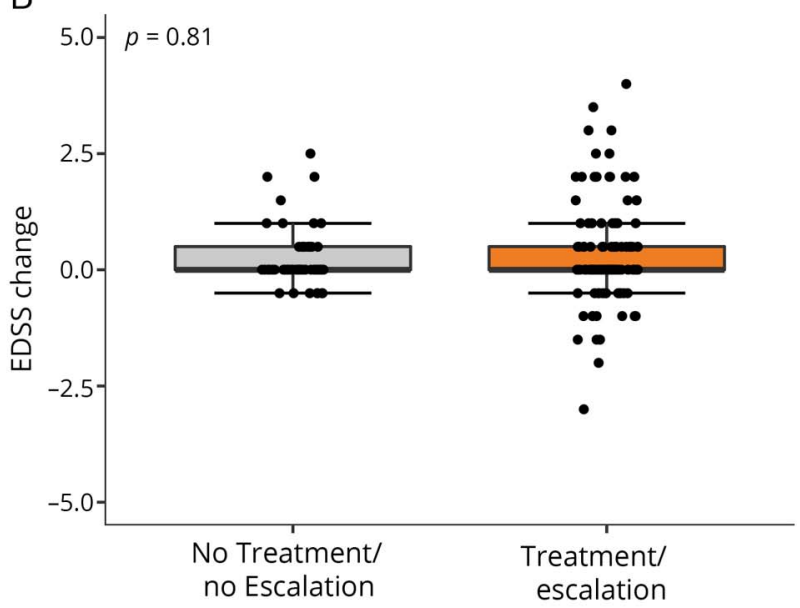

Box plots representing (A) the influence of CSF NfL on No Treatment/No Escalation vs Treatment/Escalation strategies. The horizontal black line indicates the age-specific reference value for CSF NfL (<30: $290 \mathrm{pg} / \mathrm{mL}, 30-39: 380 \mathrm{pg} / \mathrm{mL}, 40-59: 830 \mathrm{pg} / \mathrm{mL}$ ). (B) EDSS change at 1-year follow-up as a function of treatment strategies (i.e., No Treatment/No Escalation vs Treatment/Escalation) $(\mathrm{n}=203)$. Box-whisker plots represent median, quartiles, and $1.5 \times$ interquartile range. $p$ Values were obtained using the Kruskal-Wallis test. EDSS = Expanded Disability Status Scale; NfL = neurofilament light chain. 
active disease for DMT escalation, the test might also have the beneficial effect of reducing the escalation to highly active treatments in those with lower disease activity. However, more detailed qualitative work is needed to explore this in greater detail.

The main limitation of our study is the observational nature of the recorded data. Data regarding treatment strategies were retrieved from the electronic medical records and are therefore prone to reporting bias. Therefore, the influence of comorbidities, intolerance, or poor adherence to prior treatments and preferences of patients and neurologists on treatment strategies could not be accounted for in our analysis. ${ }^{31}$ An additional limitation of our study may lie in our categorization of treatment strategies, which was based on NHS England treatment algorithms and local policies. ${ }^{19}$ Some of the patients with higher levels of disability received off-label subcutaneous cladribine. Therefore, our results may not always be generalizable to practices elsewhere. We further acknowledge that normative data for CSF NfL age-related cutoffs were based on a small group of individuals. However, CSF collection is relatively invasive precluding the conduction of large-scale validation studies with healthy volunteers. Moreover, CSF NfL age-related cutoffs reported by UmanDiagnostics are in line with CSF NfL measurements reported by others and have also been used in different research settings. ${ }^{20,32}$ Finally, this was not a randomized study, and we therefore acknowledge that the differences of baseline characteristics between groups may not be randomly distributed. As such, future studies should aim to balance groups to prevent such differences.

Taken together, the findings from this study demonstrate that CSF NfL measurements can be adopted in routine clinical practice in MS. They complement established markers of disease activity to guide treatment strategies. The test may have a specific utility in patients with PMS where both clinical and MRI activity are more likely to be stable. The CSF NfL test has been adopted into our practice and has an impact on clinical outcomes based on EDSS progression.

\section{Acknowledgment}

The authors are grateful for the enthusiastic support by the clinical Barts-MS team based at The Royal London Hospital including Áine Redfern-Walsh, Andrea Stennett, Emma Ridgway, Freya Edwards, Gillian Stewart, Grace Anjorin, Philippa Hendrie, Tatiana Sayali, Thamanna Begum, and Xia Zhou.

\section{Study funding}

S. Reyes and I. Smets have been supported by 2019/20 ECTRIMS Clinical Training fellowships.

\section{Disclosure}

S. Reyes, I. Smets, and D. Holden report no disclosures. K. Carrillo-Loza has received speaking honoraria from Procter
\& Gamble. T. Christmas, L. Bianchi, and F. Ammoscato report no disclosures. B. Turner has received honoraria, travel grants, and been a member of advisory boards for Biogen, Merck Serono, Novartis, Sanofi Genzyme, and Roche. M. Marta has received honoraria and travel costs from Genzyme, AbbVie, Roche, and Novartis. K. Schmierer has received speaking honoraria, meeting support, or scientific advisory fees from Biogen, EMD Serono, Merck Serono, Novartis, Roche, Sanofi Genzyme, and Teva. G. Giovannoni has received consultancy, presentation fees, or grants from AbbVie Biotherapeutics, Bayer HealthCare, Biogen, Canbex, Celgene, Ironwood, Japan Tobacco, Novartis, Roche, Sanofi Genzyme, Synthon, Takeda, Teva, and Vertex. S. Gnanapavan has received honoraria from Biogen Idec, Sanofi Genzyme, Janssen Cilag, Merck, Neurodiem, Novartis, Roche, and Teva and grant support from ECTRIMS, Genzyme, Merck, National MS Society, Takeda, and UK MS Society. Go to Neurology.org/NN for full disclosures.

\section{Publication history}

Received by Neurology: Neuroimmunology \& Neuroinflammation April 27, 2020. Accepted in final form July 20, 2020.

\section{Appendix Authors}

\begin{tabular}{lll}
\hline Name & Location & Contribution \\
\hline $\begin{array}{l}\text { Saúl Reyes, } \\
\text { MD }\end{array}$ & $\begin{array}{l}\text { Queen Mary } \\
\text { University of London, } \\
\text { United Kingdom }\end{array}$ & $\begin{array}{l}\text { Design and conceptualization } \\
\text { of the study, major role in the } \\
\text { acquisition of data, analysis } \\
\text { and interpretation of the data, } \\
\text { and drafting and revising the } \\
\text { manuscript for intellectual } \\
\text { content }\end{array}$ \\
\hline
\end{tabular}

\begin{tabular}{|c|c|c|}
\hline $\begin{array}{l}\text { Ide Smets, } \\
\text { PhD }\end{array}$ & $\begin{array}{l}\text { Queen Mary } \\
\text { University of London, } \\
\text { United Kingdom }\end{array}$ & $\begin{array}{l}\text { Major role in the acquisition of } \\
\text { data, analysis and } \\
\text { interpretation of the data, } \\
\text { statistical analysis, and drafting } \\
\text { and revising the manuscript for } \\
\text { intellectual content }\end{array}$ \\
\hline $\begin{array}{l}\text { David } \\
\text { Holden, PhD }\end{array}$ & $\begin{array}{l}\text { Queen Mary } \\
\text { University of London, } \\
\text { United Kingdom }\end{array}$ & $\begin{array}{l}\text { Analysis and interpretation of } \\
\text { the data and revising the } \\
\text { manuscript for intellectual } \\
\text { content }\end{array}$ \\
\hline $\begin{array}{l}\text { Karina } \\
\text { Carrillo-Loza, } \\
\text { MD }\end{array}$ & $\begin{array}{l}\text { Queen Mary } \\
\text { University of London, } \\
\text { United Kingdom }\end{array}$ & $\begin{array}{l}\text { Analysis and interpretation of } \\
\text { the data and revising the } \\
\text { manuscript for intellectual } \\
\text { content }\end{array}$ \\
\hline $\begin{array}{l}\text { Tatiana } \\
\text { Christmas, } \\
\text { MD }\end{array}$ & $\begin{array}{l}\text { Queen Mary } \\
\text { University of London, } \\
\text { United Kingdom }\end{array}$ & $\begin{array}{l}\text { Analysis and interpretation of } \\
\text { the data and revising the } \\
\text { manuscript for intellectual } \\
\text { content }\end{array}$ \\
\hline $\begin{array}{l}\text { Lucia Bianchi, } \\
\text { PhD }\end{array}$ & $\begin{array}{l}\text { Queen Mary } \\
\text { University of London, } \\
\text { United Kingdom }\end{array}$ & $\begin{array}{l}\text { Analysis and interpretation of } \\
\text { the data and revising the } \\
\text { manuscript for intellectual } \\
\text { content }\end{array}$ \\
\hline $\begin{array}{l}\text { Francesca } \\
\text { Ammoscato, } \\
\text { PhD }\end{array}$ & $\begin{array}{l}\text { Queen Mary } \\
\text { University of London, } \\
\text { United Kingdom }\end{array}$ & $\begin{array}{l}\text { Analysis and interpretation of } \\
\text { the data and revising the } \\
\text { manuscript for intellectual } \\
\text { content }\end{array}$ \\
\hline
\end{tabular}


Appendix (continued)

\begin{tabular}{lll}
\hline Name & Location & Contribution \\
\hline $\begin{array}{l}\text { Benjamin } \\
\text { Turner, MD }\end{array}$ & $\begin{array}{l}\text { Royal London } \\
\text { Hospital, London, } \\
\text { United Kingdom }\end{array}$ & $\begin{array}{l}\text { Major role in the acquisition of } \\
\text { data, analysis and } \\
\text { interpretation of the data, and } \\
\text { revising the manuscript for } \\
\text { intellectual content }\end{array}$ \\
\hline $\begin{array}{l}\text { Monica } \\
\text { Marta, PhD }\end{array}$ & $\begin{array}{l}\text { Queen Mary } \\
\text { University of London, }\end{array}$ & $\begin{array}{l}\text { Major role in the acquisition of } \\
\text { data, analysis and } \\
\text { interpretation of the data, and } \\
\text { revising the manuscript for } \\
\text { intellectual content }\end{array}$ \\
\hline
\end{tabular}

\begin{tabular}{ll}
\hline Klaus & Queen Mary \\
Schmierer, & University of London, \\
PhD & United Kingdom
\end{tabular}

Major role in the acquisition of data, analysis and interpretation of the data, and revising the manuscript for intellectual content

\begin{tabular}{ll}
\hline Gavin & Queen Mary \\
Giovannoni, & University of London, \\
PhD & United Kingdom
\end{tabular}

Design and conceptualization of the study, major role in the acquisition of data, analysis and interpretation of the data, and revising the manuscript for intellectual content

\begin{tabular}{ll}
\hline Sharmilee & Queen Mary \\
Gnanapavan, & University of London, \\
PhD & United Kingdom
\end{tabular}

Design and conceptualization of the study, major role in the acquisition of data, analysis and interpretation of the data, and revising the manuscript for intellectual content

\section{References}

1. Giovannoni G. Disease-modifying treatments for early and advanced multiple sclerosis: a new treatment paradigm. Curr Opin Neurol 2018;31:233-243. doi: 10.1097/ WCO.0000000000000561.

2. Weiner HL. The challenge of multiple sclerosis: how do we cure a chronic heterogeneous disease? Ann Neurol 2009;65:239-248. doi: 10.1002/ana.21640.

3. Rae-Grant A, Day GS, Marrie RA, et al. Practice guideline recommendations summary: disease-modifying therapies for adults with multiple sclerosis. Neurology 2018 ; 90:777-788. doi: 10.1212/WNL.0000000000005347.

4. Wattjes MP, Rovira À, Miller D, et al. Evidence-based guidelines: MAGNIMS consensus guidelines on the use of MRI in multiple sclerosis-establishing disease prognosis and monitoring patients. Nat Rev Neurol 2015;11:597-606. doi: 10.1038/nrneurol.2015.157.

5. Giovannoni G, Tomic D, Bright JR, Havrdová E. "No evident disease activity”: the use of combined assessments in the management of patients with multiple sclerosis. Mult Scler J 2017;23:1179-1187. doi: 10.1177/1352458517703193.

6. Damasceno A, Damasceno BP, Cendes F. No evidence of disease activity in multiple sclerosis: implications on cognition and brain atrophy. Mult Scler 2016;22:64-72. doi: $10.1177 / 1352458515604383$.

7. Martin SJ, McGlasson S, Hunt D, Overell J. Cerebrospinal fluid neurofilament light chain in multiple sclerosis and its subtypes: a meta-analysis of case-control studies. J Neurol Neurosurg Psychiatry 2019;90:1059-1067. doi: 10.1136/jnnp-2018-319190.

8. Dubuisson N, Puentes F, Giovannoni G, Gnanapavan S. Science is $1 \%$ inspiration and 99\% biomarkers. Mult Scler 2017;23:1442-1452. doi: 10.1177/1352458517709362.

9. Gaetani L, Blennow K, Calabresi P, Di Filippo M, Parnetti L, Zetterberg H. Neurofilament light chain as a biomarker in neurological disorders. J Neurol Neurosurg Psychiatry 2019;90:870-881. doi: 10.1136/jnnp-2018-320106.

10. Bhan A, Jacobsen C, Myhr KM, Dalen I, Lode K, Farbu E. Neurofilaments and 10-year followup in multiple sclerosis. Mult Scler J 2018;24:1301-1307. doi: 10.1177/1352458518782005.
11. Petzold A. The prognostic value of CSF neurofilaments in multiple sclerosis at 15-year follow-up. J Neurol Neurosurg Psychiatry 2015;86:1388-1390. doi: 10.1136/jnnp2014-309827.

12. Kuhle J, Disanto G, Lorscheider J, et al. Fingolimod and CSF neurofilament light chain levels in relapsing-remitting multiple sclerosis. Neurology 2015;84:1639-1643. doi: 10.1212/WNL.0000000000001491.

13. Gunnarsson M, Malmeström C, Axelsson M, et al. Axonal damage in relapsing multiple sclerosis is markedly reduced by natalizumab. Ann Neurol 2011;69:83-89. doi: 10.1002/ana.22247.

14. Yildiz O, Mao Z, Adams A, et al. Disease activity in progressive multiple sclerosis can be effectively reduced by cladribine. Mult Scler Relat Disord 2018;24:20-27. doi: 10. 1016/j.msard.2018.05.010.

15. von Elm E, Altman DG, Egger M, Pocock SJ, Gøtzsche PC, Vandenbroucke JP. The Strengthening the Reporting of Observational Studies in Epidemiology (STROBE) statement: guidelines for reporting observational studies. Lancet 2007;370 1453-1457. doi: 10.1016/S0140-6736(07)61602-X.

16. Davis A, Dobson R, Kaninia S, et al. Change practice now! Using atraumatic needles to prevent post lumbar puncture headache. Eur J Neurol 2014;21:305-311. doi: 10. 1111/ene.12307.

17. Petzold A, Altintas A, Andreoni L, et al. Neurofilament ELISA validation. J Immunol Methods 2010;352:23-31. doi: 10.1016/j.jim.2009.09.014.

18. IBL International. NF-light ${ }^{\circledR}$ (neurofilament light) ELISA instructions for use. 2015. Available at: ibl-international.com/media/catalog/product/U/D/UD51001_IFU_ EU en NF-light ELISA v2019-02.pdf. Accessed March 6, 2020.

19. NHS England. Treatment algorithm for multiple sclerosis disease-modifying therapies. 2019. Available at: england.nhs.uk/commissioning/wp-content/uploads/sites/ 12/2019/03/Treatment-Algorithm-for-Multiple-Sclerosis-Disease-Modifying-Therapies-08-03-2019-1.pdf. Accessed March 6, 2020.

20. Håkansson I, Tisell A, Cassel P, et al. Neurofilament levels, disease activity and brain volume during follow-up in multiple sclerosis. J Neuroinflammation 2018;15:209. doi: 10.1186/s12974-018-1249-7.

21. Kuhle J, Plattner K, Bestwick JP, et al. A comparative study of CSF neurofilament light and heavy chain protein in MS. Mult Scler J 2013;19:1597-1603. doi: 10.1177/ 1352458513482374

22. Damasceno A, Dias-Carneiro RPC, Moraes AS, et al. Clinical and MRI correlates of CSF neurofilament light chain levels in relapsing and progressive MS. Mult Scler Relat Disord 2019;30:149-153. doi: 10.1016/j.msard.2019.02.004.

23. ECTRIMS 2019—oral presentations. Mult Scler J 2019;25(2 suppl):3-130. doi: 10. $1177 / 1352458519868070$.

24. Forgrave LM, Ma M, Best JR, DeMarco ML. The diagnostic performance of neurofilament light chain in CSF and blood for Alzheimer's disease, frontotemporal dementia, and amyotrophic lateral sclerosis: a systematic review and meta-analysis. Alzheimers Dement (Amst) 2019;11:730-743. doi: 10.1016/j. dadm.2019.08.009.

25. Matthews PM. Chronic inflammation in multiple sclerosis - seeing what was always there. Nat Rev Neurol 2019;15:582-593. doi: 10.1038/s41582-019-0240-y.

26. Harding $\mathrm{K}$, Williams $\mathrm{O}$, Willis $\mathrm{M}$, et al. Clinical outcomes of escalation vs early intensive disease-modifying therapy in patients with multiple sclerosis. JAMA Neurol 2019;76:536-541. doi: 10.1001/jamaneurol.2018.4905.

27. Brown JWL, Coles A, Horakova D, et al. Association of initial disease-modifying therapy with later conversion to secondary progressive multiple sclerosis. JAMA 2019; 321:175-187. doi: 10.1001/jama.2018.20588.

28. Bergamaschi R, Quaglini S, Tavazzi E, et al. Immunomodulatory therapies delay disease progression in multiple sclerosis. Mult Scler 2016;22:1732-1740. doi: 10 . $1177 / 1352458512445941$.

29. Tedeholm H, Lycke J, Skoog B, et al. Time to secondary progression in patients with multiple sclerosis who were treated with first generation immunomodulating drugs. Mult Scler J 2013;19:765-774. doi: 10.1177/1352458512463764.

30. Frangogiannis NG. Biomarkers: hopes and challenges in the path from discovery to clinical practice. Transl Res 2012;159:197-204. doi: 10.1016/j.trsl.2012.01. 023.

31. Torkildsen $\varnothing$, Myhr K-M, Bø L. Disease-modifying treatments for multiple sclerosis—a review of approved medications. Eur J Neurol 2016;23(suppl 1):18-27. doi: $10.1111 /$ ene.12883.

32. Vågberg M, Norgren N, Dring A, et al. Levels and age dependency of neurofilament light and Glial Fibrillary Acidic Protein in healthy individuals and their relation to the brain parenchymal fraction. PLoS One 2015;10:e0135886. doi: 10.1371/journal. pone.0135886. 


\title{
Neurology \\ Neuroimmunology \& Neuroinflammation
}

\author{
CSF neurofilament light chain testing as an aid to determine treatment strategies in MS \\ Saúl Reyes, Ide Smets, David Holden, et al. \\ Neurol Neuroimmunol Neuroinflamm 2020;7; \\ DOI 10.1212/NXI.0000000000000880
}

This information is current as of August 21, 2020

\section{Updated Information \& Services}

\section{References}

Citations

Subspecialty Collections

Permissions \& Licensing

Reprints including high resolution figures, can be found at: http://nn.neurology.org/content/7/6/e880.full.html

This article cites 30 articles, 3 of which you can access for free at: http://nn.neurology.org/content/7/6/e880.full.html\#\#ref-list-1

This article has been cited by 1 HighWire-hosted articles: http://nn.neurology.org/content/7/6/e880.full.html\#\#otherarticles

This article, along with others on similar topics, appears in the following collection(s):

All Clinical Neurology

http://nn.neurology.org//cgi/collection/all_clinical_neurology All Demyelinating disease (CNS)

http://nn.neurology.org//cgi/collection/all_demyelinating_disease_cns Multiple sclerosis

http://nn.neurology.org//cgi/collection/multiple_sclerosis

Information about reproducing this article in parts (figures,tables) or in its entirety can be found online at:

http://nn.neurology.org/misc/about.xhtml\#permissions

Information about ordering reprints can be found online:

http://nn.neurology.org/misc/addir.xhtml\#reprintsus

Neurol Neuroimmunol Neuroinflamm is an official journal of the American Academy of Neurology.

Published since April 2014, it is an open-access, online-only, continuous publication journal. Copyright

Copyright (C) 2020 The Author(s). Published by Wolters Kluwer Health, Inc. on behalf of the American

Academy of Neurology.. All rights reserved. Online ISSN: 2332-7812.

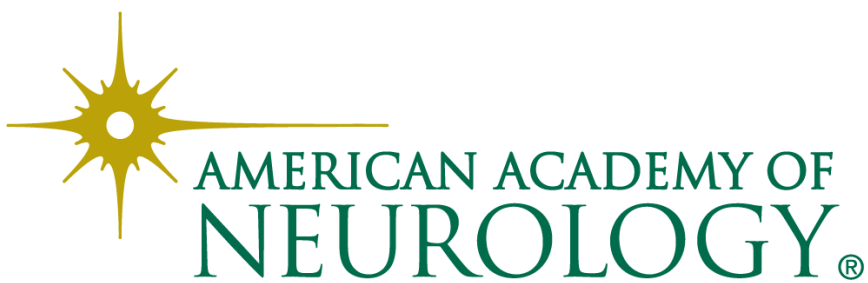

